\title{
Comparative Study of Apps Based Ride Sharing Service Uber and Regular Taxi Service Characteristics in Context of Dhaka City: A Quantitative Analysis
}

\author{
Mohammad Ahsan Uddin
}

Associate Professor, Department of Statistics, University of Dhaka, Dhaka, Bangladesh

DOI: $\underline{10.36347 / \mathrm{sjebm} .2020 . v 07 i 11.005}$

| Received: 10.11 .2020 | Accepted: 22.11.2020 | Published: 28.11 .2020

*Corresponding author: Mohammad Ahsan Uddin

Abstract

Original Research Article

Nowadays, Uber has become a very common means of transportation worldwide which connects passengers and drivers through a smartphone application. This study investigates the real scenario of the war between Uber and regular taxi service in Dhaka city to make prediction about the future of apps based ride sharing services. Popular statistical methods are adopted to make the analyses fruitful. The service quality of Uber and taxi is compared through principal component analysis and found that Uber has better services, ensuring safety through effective information dissemination. Also, Uber provides convenience through technological advancements in booking and GPS, and comfort by supplying new cars and performance conscious drivers. The binary logistic regression model gives evidence that the female and the passengers having own car/bike have less tendency to use Uber, while the higher educated persons use Uber most. It is also observed that the Uber users face less transportation problems than the taxi users. The study has found that there is a matter of satisfaction among the passengers who use Uber. The results that are obtained in this study from the statistical analyses can be used to detect the services that have low ratings, and also it will be able to give solutions to the most common problems faced by riders. Eventually, the study findings may provide an intimation about the future of Uber in Dhaka city, as well as in Bangladesh.

Keywords: Uber, taxi service, service quality, principal component analysis, binary logistic regression model.

Copyright (C) 2020 The Author(s): This is an open-access article distributed under the terms of the Creative Commons Attribution 4.0 International License (CC BY-NC 4.0) which permits unrestricted use, distribution, and reproduction in any medium for non-commercial use provided the original author and source are credited.

\section{INTRODUCTION}

Uber is a transportation network company which creates a connection among passengers and drivers using their own private passenger vehicles by means of the internet [1]. A global positioning system addresses the pick-up location of the drivers and the passengers can see the location of the closest vehicles, details of the drivers and vehicles, and estimated time of arrival [2]. The application computes the fare of the journey according to the required time and distance [3]. In recent years, there is a rapid growth of Uber as a new mode of transport in Dhaka city [4]. With the help of good social media marketing and aggressive recruitment of drivers, Uber has expanded with such a rapid rate here [5]. Usually, Uber expands its business as a ridesharing application with drivers owning their own vehicles and having another full-time job. They go for driving at their free time and make use of Uber's flexibility. In Bangladesh, the Uber business model is seemed to change as most of the drivers do not own the vehicle, and work at Uber for full-time [6].
The taxicab is still one of the prevalent forms of transportation in almost every city around the world [7]. The taxi industry is currently facing the major challenge of the technological innovation of ridesharing applications, like Uber. Uber's competitive prices are now deeply affecting this old transportation industry [8]. The main objective of the study is to conduct a perception analysis of Uber/Taxicab users and non-users to compare the service quality of this two transportation systems. Safety, drivers' performance and attitude, availability, travel time, vehicle condition, etc. are considered as a basis of this comparison. Along with this comparison, the factors that are responsible to or not to use Uber in Dhaka city are sought in this study. As this is a study on the transportation issue, whether the passengers face transportation problem is also analyzed and significant factors are detected out. The transportation problems arising from using Uber and taxi are compared. The results that are obtained in this study from the statistical analyses can be used to detect the services that have low ratings, and also it will be able to give solutions to the most common problems faced by riders. Eventually, the study findings may 
provide an intimation about the future of Uber in Dhaka city, as well as in Bangladesh.

\section{METHODS AND MATERIALS}

A primary dataset has been collected in this study during November-December 2019. We had no scope for secondary data because Uber is a recent phenomenon in Bangladesh. For the user experience and perception part of the study, a public survey has been conducted in two forms: one is by online means, posted in social media platforms (Facebook) and the other one is by physical means through handouts. For data analysis purpose, a questionnaire was made in which respondents provided data on experience, preference, and thoughts on multiple ideas about Uber and the Taxicab. Our respondents were the passengers from different areas of Dhaka city. Convenience sampling technique is used to collect a total of 300 respondents, in which 214 respondents give their information directly to the surveyors and rest 86 respondents provided their information filling up our online questionnaire.

To determine the service quality of Uber and taxi, principal component analysis (PCA) is used in this study, which reduces the number of considered variables to a fewer number of uncorrelated variables [9]. It is a widely used statistical procedure for reducing dimension of the data and clustering visualization. Principal component analysis uses an orthogonal transformation to find out principal components, which are a linear combinations of linearly uncorrelated original variables. The obtained principal components account for the most of the variability of the dataset. For the p-component random vector $\mathbf{X}$, consider the linear combinations and so on where the Y's are the required principal components which are being extracted using maximization of variance [10].

$$
\begin{aligned}
& \mathrm{Y}_{1}=\mathrm{l}_{11} \mathrm{X}_{1}+\mathrm{l}_{21} \mathrm{X}_{2}+\cdots+\mathrm{l}_{\mathrm{P} 1} \mathrm{X}_{\mathrm{P}} \\
& \mathrm{Y}_{2}=\mathrm{l}_{12} \mathrm{X}_{1}+\mathrm{l}_{22} \mathrm{X}_{2}+\cdots+\mathrm{l}_{\mathrm{P} 2} \mathrm{X}_{\mathrm{P}}
\end{aligned}
$$

Binary logistic regression analysis, a very common statistical method, is used to analyze the preference of using Uber and facing transportation problem. If the response vector $\mathbf{Y}$ be of binary type, i.e., meaning to whether an event of interest has occurred or not, binary logistic regression is used, which takes the following functional form [11]:

$$
\pi(\mathbf{x})=\frac{\mathrm{e}^{\mathbf{x}^{\prime} \boldsymbol{\beta}}}{1+\mathrm{e}^{\mathbf{x}^{\prime} \boldsymbol{\beta}}}
$$

Where $\pi(\mathbf{x})$ represents the conditional mean of $\mathbf{Y}$ given $\mathbf{x}$ i.e., $\mathrm{E}(\mathbf{Y} \mid \mathbf{x})$. The unknown parameter $\boldsymbol{\beta}$ is estimated by the method of maximum likelihood estimation $[12,13]$.

\section{RESULTS AND DISCUSSION}

To check whether the data is appropriate for principal component analysis or not, two statistics, the Keyser-Meyer-Olkin (KMO) measure of sampling adequacy and the Bartlett test of sphericity are used [14].

Table-1: KMO and Bartlett's Test for measuring sampling adequacy to perform PCA

\begin{tabular}{|l|l|l|}
\hline Kaiser-Meyer-Olkin Measure of Sampling Adequacy & 0.773 \\
\hline Bartlett's Test of Sphericity & Chi-Square value & 1305.079 \\
\cline { 2 - 3 } & DF & 91 \\
\cline { 2 - 3 } & p-value & $<0.001$ \\
\hline
\end{tabular}

The KMO measure of sampling adequacy is used to test whether the partial correlations among variables are small in which high values (closer to 1.0) indicate that a factor analysis may be useful for the data. The calculated value of the KMO statistic is 0.773 , which indicates that the dataset is appropriate for factor analysis. Bartlett's test of sphericity tests the following hypothesis:

$\mathrm{H}_{0}$ : The correlation matrix is an identity matrix

$\mathrm{H}_{1}$ : The correlation matrix is not an identity matrix

Failure to reject $\mathrm{H}_{0}$ indicates that the variables are uncorrelated. The p-value of the test for the data is less than 0.001 indicating the variables are indeed correlated and that a factor analysis can be performed in this dataset.
Table-2: Communalities obtained from PCA analysis

\begin{tabular}{|l|l|l|}
\hline & Initial & Extraction \\
\hline Convenience & 1.000 & 0.677 \\
\hline Availability of taxi & 1.000 & 0.633 \\
\hline Availability of Uber & 1.000 & 0.606 \\
\hline Travel time & 1.000 & 0.583 \\
\hline Luggage & 1.000 & 0.387 \\
\hline Destination & 1.000 & 0.581 \\
\hline Vehicle condition & 1.000 & 0.636 \\
\hline Driver attitude & 1.000 & 0.657 \\
\hline Girls safety in Uber & 1.000 & 0.719 \\
\hline Girls safety in taxi & 1.000 & 0.608 \\
\hline Night safety in Uber & 1.000 & 0.705 \\
\hline Night safety in taxi & 1.000 & 0.693 \\
\hline Uber driver performance & 1.000 & 0.708 \\
\hline Taxi driver performance & 1.000 & 0.532 \\
\hline
\end{tabular}


Communality expresses the total amount of variance that an original variable share with all other variables included in the analysis [15]. One is the initial value of each communality. In Table-2, we observe that the extracted value of the variable 'convenience' is 0.677 which indicates that about $67.7 \%$ variation in 'convenience' is explained by the principal factors. Similarly, 'Uber driver performance' has a value of
0.708 indicating that about $70.8 \%$ of its variation is explained by the principal factors. We see that most of the values are greater than 0.6 , some in between $0.5-0.6$, which means that the model is performing quite well in explaining the variation in the data. The lowest value (0.387) is found for 'luggage', which is the least explained variable.

Table-3: Result on total explained variance from PCA analysis

\begin{tabular}{|l|l|l|l|l|l|l|l|}
\hline \multicolumn{2}{|l|}{ Total Variance Explained } \\
\hline Component & \multicolumn{2}{|l|}{ Initial Eigenvalues } & \multicolumn{2}{l|}{$\begin{array}{l}\text { Extraction Sums of Squared Loadings } \\
\text { Rotation Sums of Squared } \\
\text { Loadings }\end{array}$} \\
\cline { 2 - 8 } & Total & $\begin{array}{l}\text { \% of } \\
\text { Variance }\end{array}$ & $\begin{array}{l}\text { Cumulative } \\
\%\end{array}$ & Total & $\begin{array}{l}\text { \% of } \\
\text { Variance }\end{array}$ & $\begin{array}{l}\text { Cumulative } \\
\%\end{array}$ & Total \\
\hline 1 & 4.039 & 28.849 & 28.849 & 4.039 & 28.849 & 28.849 & 3.066 \\
\hline 2 & 2.019 & 14.424 & 43.273 & 2.019 & 14.424 & 43.273 & 3.179 \\
\hline 3 & 1.635 & 11.676 & 54.949 & 1.635 & 11.676 & 54.949 & 1.773 \\
\hline 4 & 1.033 & 7.376 & 62.325 & 1.033 & 7.376 & 62.325 & 1.580 \\
\hline 5 & 0.869 & 6.210 & 68.535 & & & & \\
\hline 6 & 0.777 & 5.553 & 74.088 & & & & \\
\hline 7 & 0.705 & 5.034 & 79.122 & & & & \\
\hline 8 & 0.548 & 3.916 & 83.038 & & & & \\
\hline 9 & 0.542 & 3.869 & 86.907 & & & & \\
\hline 10 & 0.472 & 3.369 & 90.276 & & & & \\
\hline 11 & 0.447 & 3.196 & 93.473 & & & & \\
\hline 12 & 0.346 & 2.468 & 95.941 & & & & \\
\hline 13 & 0.311 & 2.221 & 98.162 & & & & \\
\hline 14 & 0.257 & 1.838 & 100.000 & & & & \\
\hline
\end{tabular}

Table- 3 shows the eigen values and how much of the data can be explained by the extracted factors, where we select variables with eigen values > 1 [16]. Thus, based on the table, the first 4 components may be considered as factors. We observe that the first factor explains $28.85 \%$ of the variation in the data. Similarly, factor 2,3 , and 4 explains $14.42 \%, 11.68 \%$, and $7.38 \%$ variation, respectively. The 4 factors together explain about $62.3 \%$ of the variation in the data which is quite good.

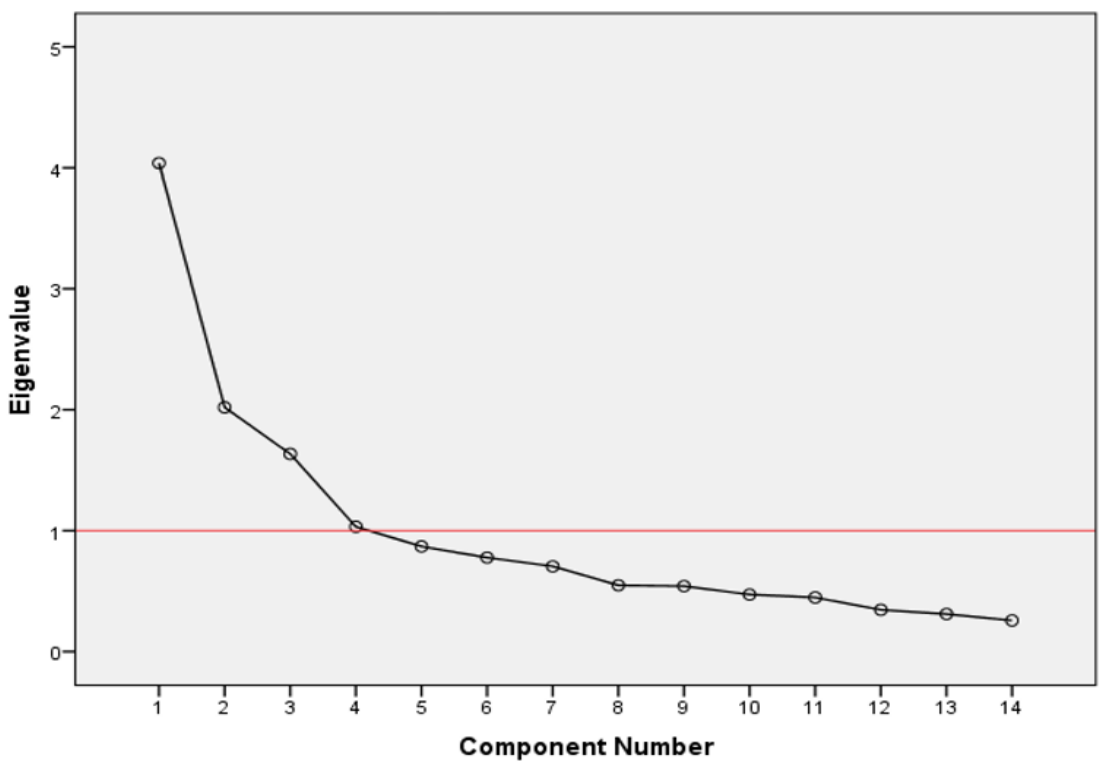

Fig-1: Scree plot obtained from PCA analysis

The scree plot plots the eigen values for each component [17]. We observe from the scree plot that the eigen values drop somewhat rapidly from components 1 to 4 and then decreases at a steady rate.
The straight line $y=1$ is considered to find out the component having eigen value at least one, and it is found that 4 components are above it. So, we have selected four components. 
Table-4: Rotated component matrix from PCA analysis

\begin{tabular}{|l|l|l|l|l|}
\hline \multirow{2}{*}{} & \multicolumn{5}{l}{ Component } \\
\cline { 2 - 5 } & $\mathbf{1}$ & $\mathbf{2}$ & $\mathbf{3}$ & $\mathbf{4}$ \\
\hline Convenience & 0.751 & -0.027 & 0.299 & -0.151 \\
\hline Availability of taxi & 0.008 & 0.260 & -0.151 & 0.737 \\
\hline Availability of Uber & 0.370 & 0.370 & 0.478 & 0.323 \\
\hline Travel time & 0.463 & -0.061 & 0.476 & 0.371 \\
\hline Luggage & 0.011 & 0.047 & 0.613 & -0.094 \\
\hline Destination & 0.379 & 0.215 & 0.473 & 0.409 \\
\hline Vehicle condition & 0.759 & 0.032 & 0.047 & 0.239 \\
\hline Driver attitude & 0.720 & 0.171 & -0.284 & 0.171 \\
\hline Girls safety in Uber & 0.248 & 0.743 & 0.193 & 0.262 \\
\hline Girls safety in taxi & 0.039 & 0.607 & -0.048 & 0.486 \\
\hline Night safety in Uber & 0.190 & 0.773 & 0.252 & 0.089 \\
\hline Night safety in taxi & -0.111 & 0.824 & -0.029 & -0.017 \\
\hline Uber driver performance & 0.664 & 0.226 & -0.251 & -0.390 \\
\hline Taxi driver performance & 0.175 & -0.113 & -0.696 & 0.061 \\
\hline
\end{tabular}

The rotated component matrix in Table-4 gives the factor loadings, the correlations of each of the original variables with each component [18]. We select the variables which have strong correlation with the components. We have selected a value of 0.5 as a threshold. With respect to the threshold value, we then select the corresponding variables for each principal component. According to the above analysis, the selected factors are summarized in Table 5 as follows:

Table-5: Variables included in factors from PCA analysis

\begin{tabular}{|l|l|}
\hline Principal Components & Included Variables \\
\hline Principal Component 1 & convenience, vehicle condition, driver attitude, Uber driver performance \\
\hline Principal Component 2 & girls' safety in Uber \& taxi, night safety in Uber \& taxi \\
\hline Principal Component 3 & luggage, taxi driver performance \\
\hline Principal Component 4 & availability of taxi \\
\hline
\end{tabular}

We observe from Table-5 that the first principal component is strongly correlated with convenience, vehicle condition, drivers' attitude and Uber driver performance. This suggests that these four criteria vary together. All the correlations are found positive which suggests that if one of the variables increases, the others also tend to increase. Similar is the case of the second principal component with four variables, girls' safety in Uber \& taxi, night safety in Uber \& taxi. We have two strongly correlated variables for the third component, one has positive and the other has negative correlation. This suggests that when luggage increases, taxi driver performance decreases. There is only one highly correlated variable for the fourth principal component which is availability of taxi. Now finally, we go for the descriptive statistics of the original variables to have an idea of which one is better, Uber or taxi on the basis of the principal components. If mean value is found closer to 1 , it indicates agreement, whereas mean value closer to 5 indicates disagreement.
Table-6: Descriptive statistics of the variables

\begin{tabular}{|l|l|l|}
\hline Variable & Mean & Std. \\
\hline Convenience & 1.77 & 0.674 \\
\hline Availability of taxi & 3.44 & 0.828 \\
\hline Availability of Uber & 2.45 & 1.011 \\
\hline Travel time & 2.14 & 0.810 \\
\hline Luggage & 2.95 & 0.880 \\
\hline Destination & 2.15 & 0.894 \\
\hline Vehicle condition & 1.98 & 0.758 \\
\hline Driver attitude & 2.20 & 0.900 \\
\hline Girls safety in Uber & 2.88 & 0.993 \\
\hline Girls safety in taxi & 3.41 & 0.817 \\
\hline Night safety in Uber & 2.99 & 0.946 \\
\hline Night safety in taxi & 3.36 & 0.908 \\
\hline Uber driver performance & 2.23 & 0.679 \\
\hline Taxi driver performance & 2.68 & 0.834 \\
\hline
\end{tabular}

Firstly, we observe the variables under the first principal component. It is found that all values are close to 1. This is an indication that passengers think Uber riding as more convenient than taxi riding. They also 
choose that the vehicle condition of Uber is better than that of the taxi. It is also evident that the performance and attitude of the Uber drivers are thought better than that of the taxi drivers. The second principal component is concerned with the safety issue. It shows that respondents agree on the point that Uber is safe in case of girls and also at night. On the contrary, they almost agree that taxi is more or less unsafe at night, and for the girls. The third component says that the performance of the taxi drivers is quite good. Lastly, passengers show concern on the issue of availability of taxis. So, considering the above results, it may be concluded that Uber scores better than the regular taxi in terms of service, more specifically, in terms of performance and safety issues.

Table-7: Binary logistic regression model estimates of the selected covariates for preference of using Uber along with odds ratio (OR), standard error (SE), and p-value

\begin{tabular}{|c|c|c|c|c|}
\hline Covariates & Coefficient & OR & SE & p-value \\
\hline Age & 0.022 & 1.022 & 0.034 & 0.521 \\
\hline \multicolumn{5}{|l|}{ Gender } \\
\hline Female & -1.462 & 0.232 & 0.594 & 0.014 \\
\hline Male & - & - & - & - \\
\hline \multicolumn{5}{|l|}{ Social status } \\
\hline Poor & 36.914 & $>50.000$ & $>50.000$ & 0.999 \\
\hline Lower Middle & 4.241 & $>50.000$ & $>50.000$ & 1.00 \\
\hline Middle & -14.663 & $<0.001$ & $>50.000$ & 0.998 \\
\hline Upper Middle & -14.091 & $<0.001$ & $>50.000$ & 0.998 \\
\hline Rich & - & - & - & - \\
\hline \multicolumn{5}{|l|}{ Marital status } \\
\hline Married & -31.322 & $<0.001$ & $>50.000$ & 0.999 \\
\hline Unmarried & -31.038 & $<0.001$ & $>50.000$ & 0.999 \\
\hline Widow & - & - & - & - \\
\hline \multicolumn{5}{|l|}{ Income (thousand) } \\
\hline$<10$ & -14.470 & $<0.001$ & $>50.000$ & 0.998 \\
\hline $10-20$ & -15.364 & $<0.001$ & $>50.000$ & 0.998 \\
\hline $20-30$ & -10.830 & $<0.001$ & $>50.000$ & 0.999 \\
\hline $30-50$ & -15.581 & $<0.001$ & $>50.000$ & 0.998 \\
\hline $50-100$ & -15.320 & $<0.001$ & $>50.000$ & 0.998 \\
\hline$>100$ & - & - & - & - \\
\hline \multicolumn{5}{|c|}{ Family income (thousand) } \\
\hline$<10$ & -20.006 & $<0.001$ & $>50.000$ & 0.999 \\
\hline $10-20$ & 13.968 & $>50.000$ & $>50.000$ & 0.999 \\
\hline $20-30$ & -2.388 & 0.092 & 1.519 & 0.116 \\
\hline $30-50$ & -2.705 & 0.067 & 1.123 & 0.216 \\
\hline $50-100$ & -1.977 & 0.138 & 0.965 & 0.140 \\
\hline$>100$ & - & - & - & - \\
\hline \multicolumn{5}{|l|}{ Internet status } \\
\hline Yes & -54.410 & $<0.001$ & $>50.000$ & 0.997 \\
\hline No & - & - & - & - \\
\hline \multicolumn{5}{|l|}{ Having car/bike } \\
\hline Yes & -1.420 & 0.242 & 0.580 & 0.014 \\
\hline No & - & - & - & - \\
\hline \multicolumn{5}{|c|}{ Frequency of transportation } \\
\hline Less than ten & -20.173 & $<0.001$ & $>50.000$ & 0.997 \\
\hline Ten to twenty & -18.511 & $<0.001$ & $>50.000$ & 0.997 \\
\hline Twenty to thirty & -19.207 & $<0.001$ & $>50.000$ & 0.997 \\
\hline Thirty to fifty & -18.773 & $<0.001$ & $>50.000$ & 0.997 \\
\hline More than fifty & - & - & - & - \\
\hline \multicolumn{5}{|c|}{ Factors in choosing transportation } \\
\hline Safety & -12.374 & $<0.001$ & $>50.000$ & 0.999 \\
\hline Price & -11.185 & $<0.001$ & $>50.000$ & 0.999 \\
\hline Ease of use & -12.924 & $<0.001$ & $>50.000$ & 0.999 \\
\hline Other & - & - & - & - \\
\hline \multicolumn{5}{|l|}{ Education status } \\
\hline Secondary & -3.734 & 0.024 & 1.252 & 0.003 \\
\hline Higher secondary & -2.654 & 0.070 & 0.708 & $<0.001$ \\
\hline Higher & - & - & - & - \\
\hline Constant & $>50.000$ & $>50.000$ & $>50.000$ & 0.998 \\
\hline
\end{tabular}


Table-7 represents the binary logistic regression model results to detect out the relevant factors for the passengers' preference of being Uber user or not. It is found that the variables gender, having car/bike, and education status are significant in the model at $5 \%$ significance level, while age, social status, marital status, income, family income, internet status, frequency of transportation, and factors in choosing transportation are insignificant. The variable gender is significant under $5 \%$ level of significance since p-value is 0.014 , which is less than 0.05 . A female passenger has $(1-0.232) \times 100 \%=76.8 \%$ lower odds of being
Uber user compared to a male passenger, keeping all other variables constant. For the variable having car/bike, an individual who has car or bike has significantly $75.8 \%$ lower odds of being Uber user compared to an individual who has no car or bike with $\mathrm{p}$-value 0.014. The variable education status is highly significant under $1 \%$ level of significance ( $p$-value $<0.001)$. The individuals whose educational qualification is secondary and higher secondary have $97.6 \%$ and $93 \%$ lower odds, respectively, of being Uber user to an individual whose educational qualification is higher.

Table-8: Binary logistic regression model estimates of the selected covariates for facing transportation problem along with standard error (SE), odds ratio (OR), and p-value

\begin{tabular}{|c|c|c|c|c|}
\hline Covariates & Coefficient & SE & OR & p-value \\
\hline Age & 0.061 & 0.029 & 1.063 & 0.034 \\
\hline \multicolumn{5}{|l|}{ Gender } \\
\hline Male & -0.639 & 0.461 & 0.528 & 0.166 \\
\hline Female & - & - & - & - \\
\hline \multicolumn{5}{|l|}{ Social status } \\
\hline Poor & $>50.000$ & $>50.000$ & $>50.000$ & 0.998 \\
\hline Lower middle & 18.579 & $>50.000$ & $>50.000$ & 0.998 \\
\hline Middle & 20.595 & $>50.000$ & $>50.000$ & 0.998 \\
\hline Upper Middle & 20.210 & $>50.000$ & $>50.000$ & 0.998 \\
\hline Rich & - & - & - & - \\
\hline \multicolumn{5}{|c|}{ Income (thousand) } \\
\hline$<<10$ & 0.781 & 1.418 & 2.183 & 0.582 \\
\hline $10-20$ & 1.079 & 1.445 & 2.941 & 0.456 \\
\hline $20-30$ & 1.373 & 1.484 & 3.948 & 0.355 \\
\hline $30-50$ & 1.675 & 1.333 & 5.339 & 0.209 \\
\hline $50-100$ & -2.911 & 1.465 & 0.054 & 0.047 \\
\hline$>100$ & - & - & - & - \\
\hline \multicolumn{5}{|c|}{ Family income (thousand) } \\
\hline$<10$ & -20.737 & $>50.000$ & $<0.001$ & 0.999 \\
\hline $10-20$ & -2.712 & 1.674 & 0.066 & 0.105 \\
\hline $20-30$ & -1.250 & 1.027 & 0.287 & 0.223 \\
\hline $30-50$ & -2.402 & 0.782 & 0.091 & 0.232 \\
\hline $50-100$ & -0.960 & 0.580 & 0.383 & 0.198 \\
\hline$>100$ & - & - & - & - \\
\hline \multicolumn{5}{|c|}{ Frequency of transportation } \\
\hline Less than ten & -0.450 & 0.833 & 0.638 & 0.589 \\
\hline Ten to twenty & 0.214 & 0.834 & 1.238 & 0.798 \\
\hline Twenty to thirty & -0.017 & 0.749 & 0.984 & 0.982 \\
\hline Thirty to fifty & 1.918 & 0.777 & 6.807 & 0.014 \\
\hline More than fifty & - & - & - & - \\
\hline \multicolumn{5}{|c|}{ Factors in choosing transportation } \\
\hline Safety & $>50.000$ & $>50.000$ & $>50.000$ & 0.999 \\
\hline Price & $>50.000$ & $>50.000$ & $>50.000$ & 0.998 \\
\hline Ease of use & $>50.000$ & $>50.000$ & $>50.000$ & 0.999 \\
\hline Other & - & - & - & - \\
\hline \multicolumn{5}{|l|}{ User type } \\
\hline Taxicab & 2.664 & 0.576 & 14.360 & $<0.001$ \\
\hline Uber & - & - & - & - \\
\hline \multicolumn{5}{|l|}{ Education Status } \\
\hline Illiterate & -0.278 & 1.305 & 0.758 & 0.832 \\
\hline Primary & 0.130 & 0.591 & 1.139 & 0.826 \\
\hline Higher & - & - & - & - \\
\hline \multicolumn{5}{|l|}{ Marital status } \\
\hline Married & -23.093 & $>50.000$ & $<0.001$ & 0.999 \\
\hline Unmarried & -23.094 & $>50.000$ & $<0.001$ & 0.999 \\
\hline Widow & - & - & - & - \\
\hline Constant & -53.286 & $>50.000$ & $<0.001$ & 0.999 \\
\hline
\end{tabular}


Table-8 is presenting the binary logistic regression model results and provides the significant factors on whether passengers face transportation problem or not. The variables age, income, frequency of transportation, and user type are found significant in the model, while gender, social status, family income, factors in choosing transportation, education status, and marital status are insignificant. The variable age is significant at $5 \%$ level of significance since p-value is 0.034 , which is less than 0.05 . For one-year increase in age, the chance of facing transportation related problem increases $(1.063-1) \times 100 \%=6.3 \%$ on an average, keeping all other variables at fixed level. For the variable income, a passenger having income in the range of fifty thousand to one lakh taka has significantly $94.6 \%$ lower odds of facing transportation problem comparative to a passenger of having income more than one lakh taka having p-value 0.047 . The regression coefficient for the other categories of this variable are insignificant under $5 \%$ level of significance. The variable frequency of transportation is significant in the model and tells that an individual who has to transport thirty to fifty times in a month has significantly (p-value 0.014) 6.807 times greater odds of facing transportation related problem compared to an individual who has to transport more than fifty times per month on an average. For the variable user type, the passenger who uses only taxicab has significantly 14.360 times greater odds of facing transportation related problem on an average compared to the passenger who uses Uber, where p-value is less than 0.001 .

From the principal component analysis part, it is observed that Uber riding is more convenient to the passengers compared to taxi riding, and the vehicle condition of Uber is better than that of taxi cabs. The performance of Uber drivers is better than that of taxi drivers. On the safety issue at night and for the girls, passengers think that Uber is more reliable [19]. The binary logistic regression part for analyzing passengers' preference to use Uber or not provides gender, having car/bike, and education status as responsible determinants. Male passengers are more prone to use Uber compared to the females [20]. It is pre-assumed and also found in the result that the respondents having car or bike have a small chance to use Uber. According to the result, the higher educated persons usually use Uber more frequently [21]. Another binary logistic regression is involved to find out significant factors on whether passengers face transportation problem or not. The analysis says that increase in age increases the chance of facing transportation problem. It is found that the persons with income range of fifty thousand to one lakh taka face the least transportation problem. The individuals who have to transport thirty to fifty times in a month face transportation problem most. Lastly, an important finding is observed that the passengers who use only taxicab have greater risk of facing transportation related problem compared to the Uber users.

\section{CONCLUSIONS}

The survey concludes that Uber has better services and creates a negative perception on the regular taxicab. Uber has an edge in safety through effective information dissemination, convenience through technological advancements in booking and GPS, and comfort through newer cars and performance conscious drivers. Assuming both modes have the same price and service most users will prefer Uber. The addition of various features and services provided by apps based ride, Uber has made easy to travel at anytime from anywhere in Dhaka city. The comparison of Uber and regular taxi service has been made here just from the view of the passengers. The study has found that there is a matter of satisfaction among the passengers who use Uber. From the findings of this study it can be recommended that if a new person or company wants to join the market of apps based ride sharing they should launch features and services consumer are preferring most and also upgrade the quality of the services with better technology so that the consumers are satisfied. They can make their advertisements more effective by reaching to the potential individuals using the result of this study. This study focuses in transportation system of Dhaka city. Therefore, the result of study may not be generalized to other part of the world. However, a comparative study can be done in future to look in the differences of two different transportation system, from the view of the drivers.

\section{REFERENCES}

1. Nistal PD, Regidor JRF, editors. Comparative study of Uber and regular taxi service characteristics. Proceedings of the 23rd Annual Conference of the Transportation Science Society of the Philippines, Quezon City, Philippines Available from: http://ncts upd edu ph/tssp/wpcontent/upload/2016/08/Paronda-et-al pdf (accessed August 13, 2017); 2016.

2. Hyder Y. Uber's evolution from San Francisco to international disruption. University of Minnesota. 2014.

3. Alba D. The Philippines Just Made Uber Legal Everywhere. Wired (11 Mei 2015), online: https://www wired com/2015/05/uber-phillipines. 2015.

4. Noor F. Factors Affecting the Holistic Perception of Uber in Dhaka City Transportation. 2019.

5. Bappy TA, Haque SS. Examining the factors affecting passengers'satisfaction with uber car services: evidences from dhaka city. Management. 2018; 32(1).

6. Atia T. Partners and drivers attraction and retention strategies of Uber Bangladesh. 2019.

7. Rahel S. Economics of the taxi industry: An Uber shake-up. Wyoming Scholars Repository. 2016. 
8. Marten L, Ferrie J. Assessing the demand for Uber: Master's thesis, Northwestern University; 2015.

9. Wold S, Esbensen K, Geladi P. Principal component analysis. Chemometrics and intelligent laboratory systems. 1987;2(1-3):37-52.

10. Thomaz CE, Giraldi GA. A new ranking method for principal components analysis and its application to face image analysis. Image and Vision Computing. 2010;28(6):902-13.

11. Sarkar S, Midi H. Importance of assessing the model adequacy of binary logistic regression. Journal of Applied Sciences. 2010;10(6):479-86.

12. Myung IJ. Tutorial on maximum likelihood estimation. Journal of mathematical Psychology. 2003;47(1):90-100.

13. Albert A, Anderson JA. On the existence of maximum likelihood estimates in logistic regression models. Biometrika. 1984;71(1):1-10.

14. Chiciudean G, Chiciudean D. Customer Segmentation by Attributes Considered Important During the Buying Decision-Making Process for Cheese. Bulletin of University of Agricultural Sciences and Veterinary Medicine Cluj-Napoca Horticulture. 2013;70(2):287-92.
15. Kootstra GJ. Exploratory factor analysis. University of Groningen. 2004

16. Nadler B. Finite sample approximation results for principal component analysis: A matrix perturbation approach. The Annals of Statistics. 2008; 36(6):2791-817.

17. Bro R, Smilde AK. Principal component analysis. Analytical Methods. 2014;6(9):2812-31.

18. Gour L, Maurya S, Koutu G, Singh S, Shukla S, Mishra D. Characterization of rice (Oryza sativa L.) genotypes using principal component analysis including scree plot \& rotated component matrix. International Journal of Chemical Studies. 2017;5(4):975-83.

19. Feeney M. Is ridesharing safe? Cato Institute Policy Analysis. 2015(767).

20. Roy S. The impacts of gender, personality and previous use on attitude towards the sharing economy and future use of the services, 2016.

21. Alemi F, Circella G, Handy S, Mokhtarian P. What influences travelers to use Uber? Exploring the factors affecting the adoption of on-demand ride services in California. Travel Behaviour and Society. 2018; 13:88-104. 